\title{
The impact of higher psychological education on the development of students'emotional intelligence
}

\author{
Oksana Beresneva ${ }^{1}$, and Olga Kornilova ${ }^{2}$ \\ ${ }^{1}$ Private institution Educational organization of higher education "Medical University Reaviz", \\ Chkalova str., 100, 443130 Samara, Russia \\ ${ }^{2}$ Samara Branch of Moscow City University,Stara Zagora str., 76, 443081 Samara, Russia
}

\begin{abstract}
The changes taking place in our society actualize new types of relationships between people based on a humanistic, personalized approach. The transformation of human relations takes place in the process of establishing new values, so the formation of the emotional side of relations in the "person-person" system becomes particularly relevant. In Russian society, there is an increased need for qualified psychologists and their solution of current problems. The rapidly changing conditions of society formation actualize the problem that deals with the development of personal and professional qualities of psychology students, including their emotional intelligence. Emotional intelligence allows to understand and feel the necessity for a rational analysis of one's own emotions and decision-making based on this process, which means that a person can act more effectively. People with developed emotional intelligence achieve their goals more easily in interaction with others and become more efficient, productive and happy. Thus, the relevance of our research is determined both by the trends in the development of scientific knowledge and the existing needs of social practice.
\end{abstract}

\section{Introduction}

Since the beginning of the twentieth century, foreign psychology has been searching for abilities that, unlike the traditionally distinguished general intelligence, are associated with the social and emotional sphere of the psyche. Leading experts in the field of psychology of intelligence, including social intelligence (Thorndyke E, Spearman Ch., Vexler D., Gilford J., Aysenk G.) and others have argued that people differ in their ability to understand other people and manage them, i.e. to act in a reasonable way in human relations [7].

In Russian Psychology the idea of affect and interest unity found its reflection in the works of Vygotsky L.S. [4]. The scientist came to the conclusion about the existence of dynamic meaning system that represents the unity of affective and intellectual processes: "As we know, the separation of the intellectual side of our consciousness from the affective, volitional side is one of the main and fundamental vices of the entire traditional psychology" [3]. On developing L.S. Vygotskii’s ideas, Rubinshteyn S.L. has noted that thinking itself is already a unity of the emotional and rational [8]. However, the approaches to the 
understanding of the affect and interest unity in the process of human development marked by Vygotsky L.S. did not receive proper elaboration at the time [1].

\subsection{The phenomenology of emotional intelligence}

The concept of "emotional intelligence" was introduced into scientific terminology by Mayer J.D. and Salovey P. in 1990. According to them, "emotional intelligence is the ability to feel and imitate emotions, to connect emotions and thoughts, to understand the causes of emotions, and to regulate emotions in oneself and others." As Mayer J.D. and Salovey P. put it, "people who have a high level of emotional intelligence are able to more rapidly develop their abilities and use them more effectively" [15].

A number of models of emotional and social intelligence has been currently developed (Daniel Goleman, 1995; Bar-on R., 1997; Mayer J. D., Salovey P., Caruso D. 1993; Lyusin D.V., 2000; and others), and its impact on the success of different activities has been studied extensively (I. E. Yegorov, 2006;A. S. Petrovskaya, 2007; S. P. Derevyanko, 2008; and others), the structure and methods of studying emotional interest are discussed in detail (D.V. Lyusin, 2000; M.A. Manoylova, 2004; T.P. Berezovskaya, 2006; I. N. Andreev a, 2004; V.D. Shadriko b, 2010; I.V. Pluzhnikov, 2010, etc.).

In the psychological literature, 2 types of models of emotional interest are described: mixed and ability models. The mixed model considers emotional intelligence as a combination of mental and personal traits inherent in each person and includes cognitive, personal and motivational traits, thanks to which they happen to be closely adaptated to real life and the processes of co-operation [10]. The mixed models include D. Goleman's ideas about emotional intelligence. He defines them as the emotional intelligence with a set of qualities that determine the ability of a person to manage himself and his relations with other people. The model presents four main components combined into two skill sets: personal (self-awareness, self-control); social (social sensitivity and relationship management). There is another example of a mixed model represented in the concept by an Israeli psychologist Bar-On R. He introduces the emotional intelligence with the individual qualities that help them resist demands and pressure of the environment [14].

Ability models are referred to the concept of emotional intelligence proposed by Mayer J. D., Salovey P., and Caruso D. Researchers determine the emotional intelligence as the ability to perceive, evoke emotions and increase the thinking effectiveness with the help of emotions, to understand emotions and emotional knowledge, and to reflexively regulate emotions for emotional and intellectual development.

The analysis of thematic sources shows that the coefficient of emotional development can be developed throughout life. Based on this assumption, the development of emotional interest is very timely because:

- emotions have adaptive nature and prompt to person`s survival at all levels of interaction with the society;

- the development of emotional intelligence contributes to harmonious personal development and creates additional motivating factors;

- emotionality is a key factor in life's success, more substantial than the general effect. According to E.L. Yakovlev, the awareness of one's own identity is nothing more than the awareness of one's own emotional actions and states, indicating an individual attitude to what is happening [13].

\subsection{Conditions for the development of emotional intelligence}

The question of the possibilities and ways of developing emotional intelligence is particularly relevant. Mayer J. D. and his associates adhere to the position that it is not possible to increase 
the level of emotional intelligence because it is a relatively stable ability. However, it is fully possible to increase the emotional competence of the training process. Daniel Goleman and his colleagues believe that emotional intelligence can be developed. The argument for this position is that the neural pathways of the brain keep developing until the end of life. At the same time, knowledge about emotions is usually acquired in the process of learning, assimilation of life experience. From T.P. Berezovskaya's point of view, the results of empirical research indicate the possibility of developing the emotional intelligence throughout socially organized training and education [2]. Such "emotional education" can be carried out both through direct training and the creation of a certain psychological climate, involving students and teachers in joint activities.

The analysis of the Russian and foreign literature revealed the presence of a number of individual and group psychological conditions that allow to develop the individual's personal structures. They include both individual and group psychotherapy (K. Rogers, 2000; K. Rudestam, 1990, etc.); psychocorrection (A.A. Osipova, 2000; K.V. Selchenok, 1999, etc.); game activity (game therapy, communicative, role, imitative games - L.A. Petrovskaya, 2007; D. B. Elkonin, 1979; A.M. Prikhozhan, 2005, etc.). The effective means of developing the emotional intelligence is social and psychological training (K. Rudestam, 1990, I. Vachkov, 2001). In the works of E.S. Asmakovets (2001), S.P. Derevyanko (2008), M.A. Anoilova (2005), D. Goleman (2002), and A.Pannkratova (2003), there are various concepts of emotional and intellectual development, based on the use of various explanations and training techniques. The development of emotional intelligence in training groups involves actualizing and deepening the abilities to understand emotions, training the effective methods and techniques which manage emotional states and promote the use of the acquired knowledge in practice.

Thus, the purposeful development of emotional intelligence can be diverse in terms of the general methodological tendency in training skills and the conceptual research foundations.

\subsection{The role of higher psychological education in the development of emotional intelligence}

The Federal State Educational Standard of Higher Education defines the professional activity object of a social psychologist as following - the mental processes, qualities and states of a person; the subject - their manifestations in different areas of human activity, interpersonal and social interactions, ways and forms of their organization and changes caused by the external environment. In accordance with the received knowledge and skills, the specialist is ready to participate in solving complementary tasks in the realm of education, health protection, management and social assistance to the population. A psychologist as a profession belongs to the "socionomic" group of professions. Therefore, a psychologist is expected to be ready to understand different people, to know different ways of life activities.

The professional competence of a person is supposed to involve knowledge, skills, erudition and thinking ability in general, so it reveals the level of cognitive intelligence. However, in most cases a high level of general knowledge is not the only point.

While studying at the university, students develop their ideas about the emotional and strong-willed sphere, as well as gain practical skills to manage and regulate their own emotions and the emotions of people around them. Theoretical classes in the educational process are aimed, to a greater extent, at the development of the cognitive component of emotional intelligence and its components: the development of the ability to identify, verbalize, analyze one's feelings and emotions; the formation of the skill to establish a qualitative educational connection. Practical classes deal with the problems which develop the behavioral component of emotional intelligence and its components: the development of the ability to control one's state in difficult situations; the development of the ability to 
change the attitude to the problem; the improvement of the communication culture; the development of the ability to understand and predict states. Independent work of studentspsychologists includes the work with theoretical material (deepening their theoretical knowledge with the help of specialized literature and the information search in electronic library systems on a given topic, note-taking and processing of educational and scientific literature, etc.).

\section{Materials and methods of research}

Our research is based on the approach by Daniel Goleman about the emotional intelligence profile. We have assumed that the graduate-year students from the faculty of Psychology will have a higher coefficient of emotional intelligence and its components in comparison with students who are just beginners at the university.

On getting education, students develop their ideas about the emotional sphere of a person, and the components of the emotional intelligence. They accumulate practical skills in managing and regulating their own emotions and the emotions of other people.

The measurement of the level of students 'emotional intelligence was carried out by the well-known questionnaire "EQ" by N. Hall (N. Hall Emotional Intelligence Self-Evaluation), which is used to identify the abilities to understand the attitudes of individuals who are represented in emotions and to govern the emotional sphere on the basis of decisions made [11]. The questionnaire contains 5 scales (emotional awareness; management of one's own emotions; self-motivation; empathy; recognition of other people's emotions) and consists of 30 statements, each of which is supposed to be estimated with the number from "- 3 " to "+3»

The study involved 90 students from higher educational institutions of Samara city: experimental group 1 (EG1) - thirty first-year students from the Faculty of Psychology; experimental group 2 (EG2) - thirty graduate-year students from the Faculty of Psychology; control group (CG) - thirty students from the Faculty of Law.

\section{Results and discussions}

The obtained experimental data were processed by mathematical and statistical methods Utest by H.B. Mann, D.R. Whitney. The criterion is intended to determine the difference between two choices according to the level of the measured attribute. It allows to show the differences between the small samples when $\mathrm{n} 1, \mathrm{n} 2 \geq 3$ or $\mathrm{n} 1=2, \mathrm{n} 2 \geq 5$.

Based on the calculation tables of methods we got the following results:

Table 1. Summary data on diagnostics of emotional intelligence between EG1 and EG2.

\begin{tabular}{|c|c|c|c|}
\hline Scale/Ranking & EG1 & EG2 & U emp \\
\hline $\begin{array}{c}\text { Emotional } \\
\text { awareness }\end{array}$ & 734 & 1096 & $\begin{array}{c}\text { 269 } \\
\text { (significance zone) }\end{array}$ \\
\hline $\begin{array}{c}\text { Management of } \\
\text { one`s own } \\
\text { emotions }\end{array}$ & 880 & 950 & 415 \\
\hline Self-motivation & 861 & 969 & 396 \\
\hline Empathy & 812.5 & 1017.5 & 347.5 \\
\hline $\begin{array}{c}\text { Recognition of } \\
\text { other people`s } \\
\text { emotions }\end{array}$ & 858 & 972 & 359 \\
\hline Integrative level & 824 & 1006 & \\
\hline
\end{tabular}


Table 2. Summary data on the diagnostics of emotional intelligence between EG1 and CG.

\begin{tabular}{|c|c|c|c|}
\hline Scale/Ranking & EG1 & CG & U emp \\
\hline $\begin{array}{c}\text { Emotional } \\
\text { awareness }\end{array}$ & 780 & 1050 & 315 \\
\hline $\begin{array}{c}\text { Management of } \\
\text { one`s own } \\
\text { emotions }\end{array}$ & 888.5 & 941.5 & 423.5 \\
\hline Self-motivation & 824.5 & 1005.5 & 359.5 \\
\hline Empathy & 768 & 1062 & 303 \\
\hline $\begin{array}{c}\text { Recognition of } \\
\text { other peoples } \\
\text { emotions }\end{array}$ & 983.5 & 846.5 & 381.5 \\
\hline Integrative level & 794 & 1036 & 329 \\
\hline
\end{tabular}

Table 3. Summary data on the diagnostics of emotional intelligence between EG2 and CG.

\begin{tabular}{|l|c|c|c|}
\hline \multicolumn{1}{|c|}{ Scale/Ranking } & EG2 & CG & U emp \\
\hline $\begin{array}{l}\text { Emotional } \\
\text { awareness }\end{array}$ & 975.5 & 854.5 & 389.5 \\
\hline $\begin{array}{l}\text { Management of } \\
\text { one`s own } \\
\text { emotions }\end{array}$ & 918 & 912 & 447 \\
\hline Self-motivation & 873 & 957 & 408 \\
\hline Empathy of & 885 & 945 & 420 \\
\hline $\begin{array}{l}\text { Recognition pon peoples } \\
\text { other pmotions }\end{array}$ & 846.5 & 983.5 & 381.5 \\
\hline Integrative level & 954 & 876 & 411 \\
\hline
\end{tabular}

According to the differences between the groups based on the characteristics of emotional intelligence, the comparative analysis of both integrative and partial levels of emotional intelligence has showed that none of the studied students groups has a high level of emotional intelligence. In general, there prevails a low integrative level of emotional intelligence development and the average level of development of such emotional intelligence characteristics as empathy in the groups of the students we have tested.

In the EG1 group, there is a low level of emotional awareness and recognition of other people`s emotions, while in EG2 and CG there is a low level of development of the same characteristics.

The correlation analysis allowed us to reveal significant differences between the EG1 and EG2 groups. Emotional awareness in the EG1 group is significantly lower than in the EG2 group. There are no other significant differences between the EG1, EG2, and CG groups.

\section{Conclusions}

1. Education is a combination of knowledge obtained in the process of special education. A high indication in emotional awareness among graduate students, who have information and knowledge about emotions (in comparison with those who are just beginners), claims the impact of (but not enough) psychological training on the development of emotional intelligence in the direction of progressive development.

2. Psychological education does not affect the change of such characteristics of emotional intelligence as the management of one's own emotions, self-motivation, empathy and the recognition of other people's emotions. Consequently, in order to increase the integrative level of emotional intelligence, practical exercising in group training, as well as individual and group therapy are necessary to a greater extent, if the person is interested in transformation and correction. 
Thus, our assumptions that the higher psychological education sufficiently develops the emotional intelligence and its individual characteristics are partially confirmed. These conclusions allow us to justify the need to create special psychological and pedagogical conditions for the emotional intelligence development of future psychologists in the process of studying at the university and to activate the process of attracting additional resources (developing and correctional programs) in order to accompany the educational process.

\section{References}

1. I. N. Andreeva, Voprosy psikhologii, 3, 78 (2006)

2. T. P. Berezovskaya, Psychological features of emotional intelligence of high school students, 16 (2006)

3. L. S. Vygotsky, Problems of general psychology, 278 (1982)

4. L. S. Vygotsky, Problems of general psychology, 504 (1982)

5. M. A. Manojlova, Development of emotional intelligence of future teachers, 60 (2004)

6. A. A. Osipov, General psycho-correction, 509 (2002)

7. R. D. Roberts, J. Matthews, M. Zeidner, D.V. Lucien, Psychology: J. of the Higher School of Economics, 1(4), 3 (2004)

8. S. L. Rubinstein, Problems of general psychology, 247 (1976)

9. D.V. Lyusin, D.V. Ushakov, Social and emotional intelligence: from processes to dimensions, 351 (2009)

10. R. J. Sternberg, J. B. Forsyth, J. Hedland, etc., Practical intelligence, 272 (2003)

11. N. P. Fetiskin, Socio-psychological diagnostics of the development of personality and small groups: a textbook, 390 (2014)

12. D. D. Shandlorenko, Society: sociology, psychology, pedagogy, 3, 36 (2017)

13. E. L. Yakovleva, Questions of psychology, 4, 20 (1997)

14. R. Bar, On, Emotional Intelligence Inventory (EQ - i): Technical Manual, Toronto,

15. (1997)

16. J. D. Mayer, P. Salovey, Emotional Development and Emotional Intelligence: Implicati ons for Educators, 10 (1997) 